\title{
A New Technique to Achieve Sufficient Mesorectal Excision in Upper Rectal Cancer
}

\author{
Seiji Ohigashi Naoki Hayashi Gen Shimada Hisashi Onodera
}

Department of Surgery, St. Luke's International Hospital, Tokyo, Japan

\section{Key Words}

Upper rectal cancer - Partial mesorectal excision $\cdot$ Rectal

wall dissection $\cdot$ Tumor-specific mesorectal excision
PME. Conclusions: This easily performed method is a promising procedure for achieving sufficient PME in upper rectal cancer.

Copyright $\odot 2007$ S. Karger AG, Basel

\begin{abstract}
Background: Appropriate partial mesorectal excision (PME) is extremely important for prevention of local recurrence even in upper rectal cancer. However, it is not always easy to conduct PME in the narrow pelvic cavity. We devised a new surgical technique that involves a rectal transection followed by PME. Methods: After rectal mobilization in the layer targeted for total mesorectal excision, only the rectal wall was bluntly dissected at an appropriate distance from the tumor. Initial transection of the rectum allows drawing the rectum toward the anal side so that the mesorectum can be confirmed with a good visual field. Excision of the mesorectum was easy, and it could be resected in a short time. $\boldsymbol{R} \boldsymbol{e}$ sults: This technique was conducted on seven patients with upper rectal cancer and on four patients with rectosigmoid cancer. Separation of the rectal wall was comparatively easy, and we had no incidence of wall injury. The average distance from the rectal stump to the distal mesorectum in the freshly resected specimen was $15 \mathrm{~mm}$, indicating satisfactory
\end{abstract}

\section{Introduction}

Sufficient excision of the mesorectum is extremely important in preventing local recurrence not only for lower or middle rectal cancer but also for upper rectal cancer [1-3]. At the level at which total mesorectal excision is conducted, the mesorectum is thin, usually precluding the need for special treatment of the mesorectum; on the other hand, the mesorectum at the site of a partial mesorectal excision (PME) for upper rectal cancer is thick. Conventionally, the mesorectum is treated first, and then the rectum is transected. However, it is not always easy to accomplish successful PME in the narrow pelvic cavity, and insufficient PME may be associated with a risk of local recurrence $[4,5,9]$. We devised a new surgical technique to achieve sufficient mesorectal excision for upper rectal cancer.

\section{KARGER}

Fax +41613061234 E-Mail karger@karger.ch www.karger.com
(C) 2007 S. Karger AG, Basel

0253-4886/07/0243-0173\$23.50/0

Accessible online at:

www.karger.com/dsu
Seiji Ohigashi

Department of Surgery

St. Luke's International Hospital

9-1 Akashi-cho Chuo-ku, Tokyo 104-8560 (Japan)

Tel. +81 33541 5151, Fax +8133544 0649, E-Mail ohsei@luke.or.jp 


\section{Methods}

Rectal mobilization was carried out by sharp dissection under direct vision. In the target layer for total mesorectal excision, the visceral fascia was kept intact during the rectal dissection. At an appropriate distance of $4-5 \mathrm{~cm}$ from the tumor, the rectal wall dissection was begun from the right side to resect several vessels entering the rectal wall (fig. 1). Harmonic scalpel or LigaSure proved to be favorable techniques (fig. 2). After the left side vessels of the rectum were resected successively, blunt dissection of the posterior part of the rectum, where vessels were rarely observed, was carefully performed. Only the rectal tube was initially dissected all around about $2-3 \mathrm{~cm}$ from the mesorectum to create enough space to insert a stapler instrument, and then the tape was applied on the rectal tube (fig. 3). After the distal rectal stump was irrigated, the rectum was transected using a Contour Curved Cutter Stapler, enabling concurrent closure and resection in a single procedure (fig. 4). Since the rectal tube was pulled toward the cranial side during the manipulation of the stapler instrument, the rectal stump was drawn toward the anal side just after cutting off the rectum. Then, it was possible to identify the mesorectum with a good visual field where the rectum was not attached (fig. 5). Excision of the mesorectum was easy, and it could be resected in a short period of time. Reconstruction was conducted using double-stapling techniques.

\section{Results}

PME using this technique was conducted on seven patients with upper rectal cancer and on four patients with rectosigmoid cancer. There were six men and five women with an average age of 63 years (range 41-82). Separation of the rectal wall was comparatively easy, and we had no incidence of wall injury. Mean blood loss was $288 \mathrm{ml}$, and mean operating time was $2 \mathrm{~h}$ and $45 \mathrm{~min}$. No significant differences were observed compared with the 17 cases of upper rectal cancer performed by the conventional technique during the past 6 months (mean blood loss: $260 \mathrm{ml}$, mean operating time: $2 \mathrm{~h}$ and $32 \mathrm{~min})$. No patient required covering stoma, and postoperative anastomotic failure did not occur. The average distance from the rectal stump to the distal mesorectum in the freshly resected specimen was $15 \mathrm{~mm}$ (range 10-25 mm), indicating satisfactory PME (fig. 6).

\section{Discussion}

This technique is a new procedure involving a rectal approach followed by PME to achieve sufficient mesorectal excision for upper rectal cancer. The novel aspect of this technique is the resection of the several vessels entering the bilateral rectal wall as a first step. After that, blunt dissection of the rectum from the mesorectum is easy to perform because of the avascular area lying just behind the rectum. Advantages of this technique include: (1) transecting the rectum first allows placement of the distal margin at the scheduled appropriate line, and (2) initial transection of the rectum allows drawing the rectum toward the anal side so that the mesorectum can be confirmed with a good visual field. In particular, the latter advantage is important, and it is possible to resect the mesorectum at the orthogonal angle from the ventral side toward the sacrum in a short period of time.

There are some reports that ordinary PME for upper rectal cancer can provide good local control $[6,7]$. However, to conduct appropriate mesorectal excision at an adequate distance from the tumor in the narrow pelvic cavity is not always easy $[4,5,9]$. In the conventional procedure, the mesorectum is treated first and the rectum second; this approach makes it likely that PME will be resected obliquely to the anal side, introducing unnecessary and greater-than-expected rectal transection. There is also the possibility of inadequate PME shifting toward the oral side or slipping off between the right and left sides of the rectal wall.

To reduce the local recurrence rate in rectal cancer, appropriate mesorectal excision is required, corresponding to the localization or T-stage of the tumor $[5,8,10]$. We would like to emphasize that the primary advantage of our new method is that ensured tumor-specific mesorectal excision can be performed easily in a good visual field.

Fig. 1. The rectal dissection was begun from the lateral side of the rectum.

Fig. 2. Harmonic scalpel was useful to resect the small vessels entering the rectal side wall.

Fig. 3. The rectal tube was dissected from the mesorectum at an appropriate distance from the tumor, and then the tape was put on the rectum (arrows).

Fig. 4. After irrigation of the rectal stump, a Contour Curved Cutter Stapler was inserted to close the rectum.

Fig. 5. When the rectum was transected, the distal rectal stump (arrows) was drawn toward the anal side, and the mesorectum could be confirmed with a good visual field. Arrowheads show the proximal stump.

Fig. 6. The specimen was excised with sufficient mesorectum, indicating satisfactory partial mesorectal excision. 

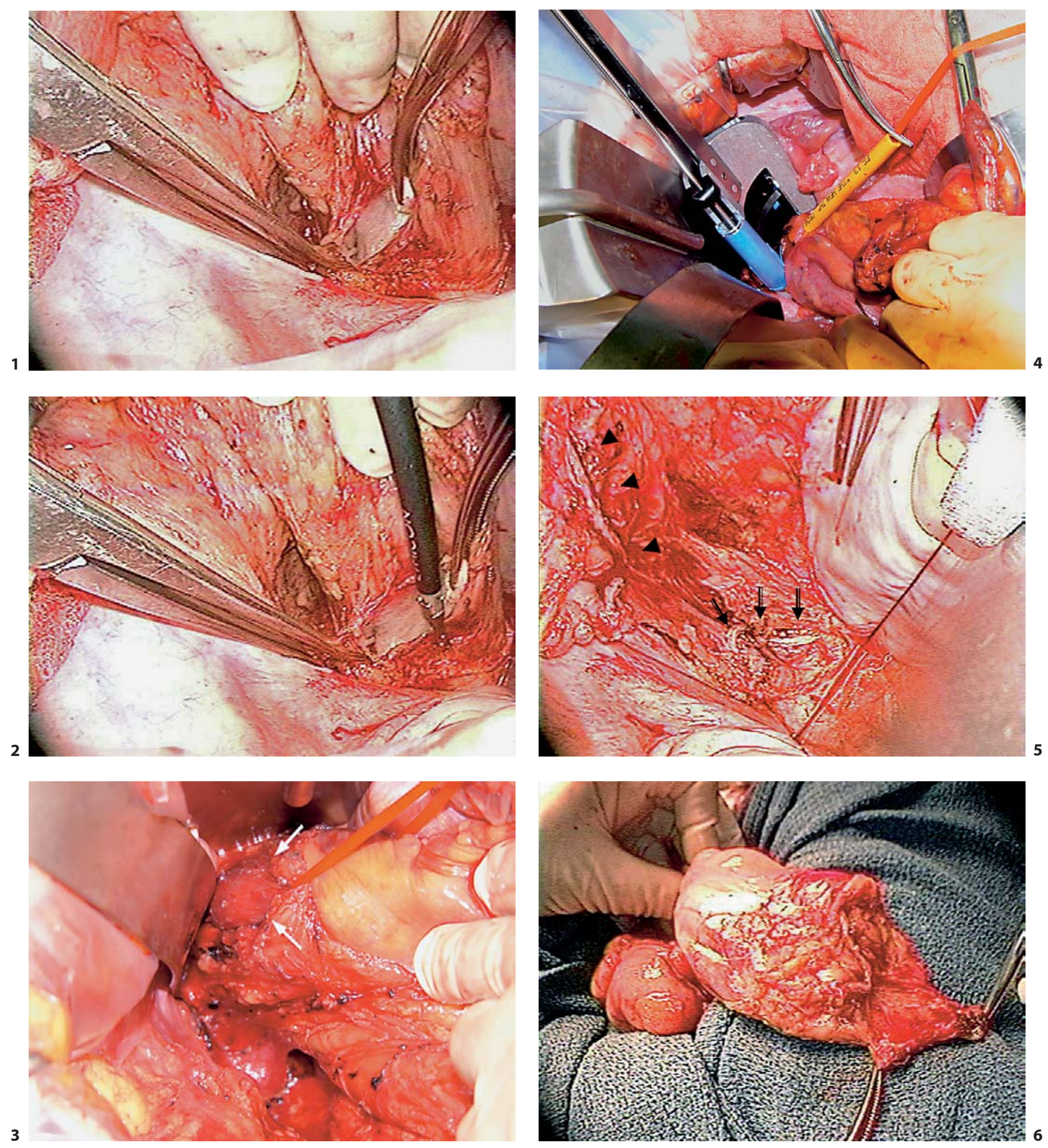


\section{References}

-1 Heald RJ, Moran BJ, Ryall RD, Sexton R, MacFarlane JK: Rectal cancer: The Basingstoke experience of total mesorectal excision, 1978-1997. Arch Surg 1998;133:894899.

-2 Enker WE, Thaler HT, Cranor ML, Polyak T: Total mesorectal excision in the operative treatment of rectal carcinoma of the rectum. J Am Coll Surg 1995;181:335-346.

$\checkmark 3$ Kapiteijn E, Marijnen CA, Nagtegaal ID, Putter H, Steup WH, Wiggers T, Rutten HJ, Pahlman L, Glimelius B, van Krieken JH, Leer JW, van de Velde CJ: Dutch Colorectal Cancer Group. Preoperative radiotherapy combined with total mesorectal excision for respectable rectal cancer. N Engl J Med 2001; 345:638-646.

4 Pakkastie TE, Luukkonen PE, Jarvinen HJ: Anastomotic leakage after anterior resection for the rectum. Eur J Surg 1994;160:293297.
5 Quirke P, Durdey P, Dixon MF, William NS Local recurrence of rectal adenocarcinoma due to inadequate surgical resection: histopathological study of lateral tumor spread and surgical excision. Lancet 1986;ii:996999.

6 Law WL, Chu KW: Anterior resection for rectal cancer with mesorectal excision: a prospective evaluation of 622 patients. Ann Surg 2004;240:260-268.

7 Lopez-Kostner F, Lavery IC, Hool GR, Rybicki LA, Fazio VW: Total mesorectal excision is not necessary for cancers of the upper rectum. Surgery 1998;124:612-617.
8 Adam IJ, Mohamdee MO, Martin IG, Scott N, Finan PJ, Jonston D, Dixson MF, Quirke P: Role of circumferential margin involvement in the local recurrence of rectal cancer. Lancet 1994;344:707-711.

-9 Zaheer S, Pemberton JH, Farouk R, Dozois RR, Wolff BG, Ilstrup D: Surgical treatment of adenocarcinoma of the rectum. Ann Surg 1998;227:800-811.

$>10$ Lowry AC, Simmang CL, Boulos P, Farmer KC, Finan PJ, Hyman N, Killingback M, Lubowski DZ, Moore R, Penfold C, Savoca P, Stitz R, Tjandra JJ: Consensus statement of definitions for anorectal physiology and rectal cancer: report of the Tripartite Consensus Conference on Definitions for Anorectal Physiology and Rectal Cancer, Washington, DC, May 1, 1999. Dis Colon Rectum 2001;44: 915-919. 